\title{
A AÇÃO POLÍTICA DA IGREJA CATÓLICA NA DITADURA MILITAR: O CASO DE SÃO CARLOS (SP) ${ }^{1}$
}

\author{
Emanuelle Kopanyshyn ${ }^{2}$
}

\section{Resumo}

Este artigo tem por objetivo fazer um estudo de caso das relações da Igreja Católica com o Estado durante a ditadura militar no Brasil (1964-1985). Mais especificamente, será abordado o caso da diocese de São Carlos, estado de São Paulo, sob a teoria do institucionalismo histórico. Como os bispos católicos durante a ditadura militar não apresentaram um comportamento único, mas tiveram a prerrogativa de autonomia em cada diocese, esse artigo apresenta sua contribuição, em âmbito local, para o conhecimento da memória histórica e da análise política dos acontecimentos da ditadura militar.

Palavras-chave: Igreja Católica; Ditadura Militar; Diocese de São Carlos.

\section{Abstract}

The aim of this article is to make a case study of the Catholic Church's relations with the State during the military dictatorship in Brazil (1964-1985). Specifically, it is going discuss the case of the diocese of São Carlos, São Paulo, using the theory of historical institutionalism. As the Catholic bishops during the military dictatorship did not have a single behavior but had the prerogative of autonomy in each diocese, this article presents its contribution at the local level, to the knowledge about historical memory and political analysis of the events of the military dictatorship.

Key-words: Catholic Church; Military dictatorship; Diocese de São Carlos.

\section{Resumen}

Este artículo tiene como objetivo hacer un estudio de caso de las relaciones de la Iglesia Católica con el Estado durante la dictadura militar en Brasil (1964-1985). Específicamente, se abordará el caso de la diócesis de São Carlos, São Paulo, con la teoría del institucionalismo histórico. Como los bispos católicos durante la dictadura militar no tenían un solo comportamiento, pero tenían la prerrogativa de la autonomía en cada diócesis, este artículo presenta su contribución en el ámbito local, para el conocimiento de la memoria histórica y el análisis política de los acontecimientos de la dictadura militar.

Palabras clave: Iglesia Católica; Dictadura militar; Diócesis de São Carlos.

\section{INTRODUÇÃO}

A temática que envolve a Igreja Católica com a ditadura militar no Brasil (1964-1985) já foi objeto de importantes análises sobre as relações entre civis e militares e sobre o alcance da articulação da sociedade civil no apoio ou na resistência ao regime. A literatura específica sobre o tema ${ }^{3}$ nos oferece possibilidades de interpretação para a ação política do clero no período, com destaque para o pensamento institucional e/ou a atuação de alguns bispos. Contudo, ainda há algumas lacunas na literatura, sobretudo nos casos de bispos com menor visibilidade em âmbito nacional, que ainda não foram objeto de análise da ciência política. $O$ que poderia explicar posicionamentos tão distintos?

\footnotetext{
${ }^{1}$ DOI deste artigo: $10.5380 /$ recp.v6i2.42551

2 Mestre em Ciência Política; Universidade Federal de São Carlos; email: emanuelle_kopany@hotmail.com

${ }^{3}$ Cf: MAIWARING, 1989; BRUNEAU, 1974; SOUZA E LIMA, 1979.
} 
Assumimos primeiramente que o sentido de missão, no sentido proposto pelo estudo de Scott Mainwaring (1989) para orientação da ação dos atores, é importante, pois ação de cada bispo deriva de sua forma de interpretação da mensagem religiosa, o que possibilita que tenham comportamentos variados dentro da própria Igreja Católica. Mainwaring, que se destaca por uma metodologia mais weberiana, trabalhou com a categoria identidade institucional da Igreja, que lhe permitiu conceber as mudanças de objetivo do catolicismo brasileiro subordinadas sempre à doutrina e à teologia eclesiástica. Para ele, as divisões eclesiásticas são condicionadas por diferentes concepções de 'missão', que orientariam os distintos membros da Igreja e as justificativas para os seus posicionamentos, inclusive políticos, se encontrariam no campo religioso e simbólico. É premissa metodológica deste estudo que o comportamento político dos bispos pode ser analisado a partir da forma como cada agente social se relaciona com as diretrizes da Igreja Católica e com seu contexto histórico-social.

Para atingir resultados mais precisos, foi necessário investigar como se dava a rede de relações que os bispos das citadas dioceses mantinham com a comunidade, os grupos e os segmentos da sociedade civil à qual estavam inseridos, pois isso possibilita ampliar qualitativamente o entendimento do processo histórico desses atores sociais e das condições e ferramentas das quais dispunham para a ação política que assumiram - determinada ação ou a inação pode ser avaliada a partir da perspectiva de análise da rede de relações.

O panorama da história do regime militar na região da diocese é essencial pois é escassa a literatura sobre esse período em no que se refere à história local envolvendo os membros da Igreja Católica. De um modo geral, a repressão policial-militar direcionada aos quadros eclesiásticos foi determinante para ação dos bispos para a adoção de posicionamento crítico da Igreja Católica em relação ao Estado. Para orientar a análise, faremos uso do institucionalismo histórico, porque considera que o processo de tomada de decisão deve ser analisado em um contexto em que as preferências já estão estruturadas e são restringidas por certo arranjo institucional (PERES, 2008).

São Carlos, a diocese que será estudada, se situa geograficamente na região central do estado de São Paulo e é, hoje, referenciada como importante polo tecnológico e de produção de conhecimento no país. No período da ditadura militar, a cidade foi cenário de acontecimentos políticos de repercussão nacional e tem em sua história as marcas deixadas por sindicalistas, líderes estudantis, industriais, políticos e militares de renome. À frente da diocese de São Carlos Borromeu, os bispos diocesanos atuaram, como autoridades eclesiásticas, no contexto não somente pastoral, mas também social e político de cada época. 
Uma rápida digressão é necessária para situar histórica e politicamente a cidade de São Carlos. No contexto da expansão da lavoura cafeeira das últimas décadas do século XIX e primeiras do século XX, a cidade foi fundada e rapidamente adquiriu um status político e econômico muito importante. A construção da estrada de ferro para escoar a produção de café até Santos e a vinda de imigrantes, sobretudo alemães e italianos, apontam os caminhos da povoação e da constituição da comunidade são-carlense. Com a crise do café após 1929, as oficinas que antes serviam ao mercado dos trabalhadores da lavoura cafeeira precisaram se reinventar, impulsionando a consolidação primeiramente da manufatura e, depois, a industrialização da região (TRUZZI, 2007). A fundação da Escola de Engenharia de São Carlos, vinculada à Universidade de São Paulo (USP), em 1953, e da Universidade Federal de São Carlos (UFSCar), em dezembro de 1968, são cruciais para a posição privilegiada da cidade em termos de desenvolvimento regional e tecnologia.

A diocese de São Carlos, por sua vez, foi fundada em 1908, elevada a partir da Diocese de São Paulo e teve papel histórico importante dentro da estrutura da Igreja Católica, uma vez que, posteriormente, foi formadora de todas as dioceses do noroeste do estado de São Paulo: a de Jaboticabal e São José do Rio Preto, em 1929, e a de Catanduva, em 2000. Após todas as perdas de território, a diocese abrange 29 municípios. Em seus mais de cem anos, a diocese teve cinco bispos diocesanos até a redação deste artigo.

Em que pese ser importante o domínio da trajetória dos líderes da diocese de São Carlos, esse estudo fará uma análise do bispo no governo no período do regime militar, Dom Ruy Serra. Segundo a documentação da diocese, Ruy Serra nasceu em 1900, no distrito de Souzas, em Campinas, entrou para a ordem dos premonstratenses ${ }^{4}$, fazendo seu noviciado no Seminário de Despere, em Chicago, Estados Unidos, em 1918. Dois anos depois, fez os Estudos Eclesiásticos Superiores na Bélgica, na Abadia de Averbode. Em 1921 retornou ao Brasil, sendo ordenado padre na diocese de São Carlos em 1923, e bispo em 1948 na mesma diocese, depois de ter exercido diversos cargos eclesiásticos. Dom Ruy é, portanto, um bispo "pré-conciliar", ou seja, sua formação remete à lógica anterior ao processo de modernização do Concílio Vaticano II, que tinha ainda a forte associação da figura do bispo com a concepção de nobreza, como "príncipe da Igreja”. Contudo, na década de 1960 foi um dos bispos que integraram o Concílio, fazendo as viagens a Roma para as reuniões do episcopado

\footnotetext{
4 Organização de religiosos regulares que seguem a Regra de Santo Agostinho, sob interpretação de seu fundador, São Norberto, assim chamados por ter sido o primeiro mosteiro em Prémonté, na diocese de Laon, na França.
} 
mundial e trazendo para a sua diocese as mudanças, sobretudo litúrgicas e pastorais a que a Igreja Universal estava se propondo.

Em relação à sua ação social e política percebe-se que o bispo diocesano segue as diretrizes da Rerum Novarum, carta publicada por Leão XXIII no fim do século XIX. Nas questões que permeiam essa temática nos boletins mensais da cúria, é comum encontrarmos publicações que problematizam a situação dos operários e agricultores sempre aos olhos da Doutrina Social da Igreja, radicalmente oposta a qualquer formação socialista e/ou comunista, mas também se opõe ao liberalismo econômico. Ainda que algumas dessas publicações nos boletins não fossem de autoria direta de Dom Ruy Serra, certamente tinham sua aprovação para circular em nome da cúria. Ou fazemos nós ou os comunistas fazem é um dos lemas encontrados (Boletim da Cúria, maio de 1962) na orientação do bispo para os padres organizarem sindicatos, custeando inclusive formações de lideranças sindicalistas da região para essa finalidade.

Importante lembrar que, a partir de 1971, Dom Ruy Serra contou com um coadjutor e administrador apostólico, Dom Constantino Almstaden, que esteve à frente principalmente de questões pastorais e burocráticas dentro da diocese até assumir como bispo diocesano em 1986.

Com a maioria da população declarada católica, a história de São Carlos se constituiu com a participação direta ou indireta das autoridades eclesiásticas, seja junto às classes dirigentes, seja junto às massas. Veremos a seguir questões importantes para o nosso tema.

\section{A TRAJETÓRIA POLÍTICA DE SÃO CARLOS NO PERÍODO QUE ANTECEDEU O REGIME MILITAR}

Apesar de a trajetória de suas lideranças políticas estar ligada à nobreza imperial e aos grandes senhores do café, inferir que São Carlos é, por esse motivo, uma cidade política e unilateralmente conservadora pode apresentar o que na Ciência Política chamamos de viés, ou seja, estabelecer uma inferência causal em relação a indivíduos, tendo como base a observação de grupos que tiveram uma exposição heterogênea ao fator observado, no caso, o conservadorismo. Contudo, se é verdade que não se deve cair no simplismo da ligação da cidade com o conservadorismo, também é verdade que não se deve rejeitar os elementos de conservadorismo político contidos na trajetória da cidade. 
Os cidadãos são-carlenses construíram um discurso muito forte de ligação aos fundadores da cidade, a família Botelho, começando com Antônio Carlos de Arruda Botelho, o Conde do Pinhal. Os Botelhos mantêm em sua tradição o imaginário das famílias "pioneiras", donas das terras desde a concessão da sesmaria do Pinhal em 1831, e membros da estrutura do Estado, como juízes, delegados, deputados, secretários, etc. A estrutura política na qual São Carlos se insere, como veremos, foi profundamente coronelística, de forma que se engajaram na defesa desse sistema em 1932, enfrentando as tropas federais com ao menos 567 pessoas e arrecadando provisões (CARNEIRO, 1977). O bispo da época, dom Marcondes, participou ativamente da campanha de levantamento de ouro. Os estudos de Kerbauy (1979) demonstram o quanto São Carlos, por ter a economia dominada pela cafeicultura, vivia sob o mandonismo local exercido pelos grandes proprietários de terra, onde a alternância de poder, quando havia, basicamente não alterava muito o cenário político. Após 1945, a passagem do regime autoritário do Estado Novo para o representativo partiu a antiga polarização ligada às famílias proprietárias de terra no município, possibilitando representação a mais segmentos da sociedade civil.

No novo sistema partidário, o diretório da UDN (União Democrática Nacional) foi organizado por iniciativa do médico e industrial Ernesto Pereira Lopes, o grande polarizador das eleições locais. O PSD (Partido Social Democrático) teve engajamento dos remanescentes das antigas famílias da cidade, como Carlos Camargo de Salles, Aldo de Cresci e Emílio Fehr. No PTB (Partido Trabalhista Brasileiro), encontravam-se à frente Domingos Mazzei e Antônio Donato. O PSP (Partido Social Progressista) trazia como principais membros Francisco Xavier do Amaral Filho, Leôncio Zambel e Alderico Vieira Perdigão. O PTN (Partido Trabalhista Nacional) teve como líderes Antônio Macei, Orlando Marques e José Bento Carlos do Amaral.

Para Kerbauy, é a partir dessa estrutura partidária que o "populismo" passa a ser exercido em território são-carlense, uma modalidade de atividade política em que há um discurso dirigido às camadas menos privilegiadas da população, mas que, não raro, praticava ações paternalistas, tendo em vista o voto popular. Todos os diretórios estavam permeados por personalismos. A UDN era frequentemente identificada pelos militantes como o "Partido dos Patrões" ou dos "Cartolas", em oposição ao que seriam os outros "Partidos do Povo”. Nas eleições locais, a tendência era a formação de duas coligações: uma capitaneada pela UDN, que geralmente tinha em sua composição o PSD e o PRP; e outra tendo à frente Antônio Massei, do PTN, com o PSP, PTB e outros de caráter populista, vitoriosos em 
praticamente todas as disputas pela prefeitura local no período que precede o regime ditatorial.

A Igreja Católica de São Carlos também se envolveu direta e indiretamente nas questões eleitorais desse período. Desde a década de 1930, a Igreja Católica no Brasil havia composto, sob liderança de Dom Sebastião Leme, arcebispo do Rio de Janeiro, a Liga Eleitoral Católica, um movimento que visava organizar os católicos e seus princípios frente à política nacional. Com o tempo e a morte desse arcebispo, essa forma de organização político-partidária dos católicos se tornou obsoleta até ser substituída por outras formas bem menos articuladas em termos nacionais, embora ainda eficazes no que se refere às eleições. O bispo de São Carlos, dom Ruy Serra, propôs à sua diocese o modelo da Aliança Eleitoral pela Família (ALEF), que substancialmente agia como uma entidade suprapartidária ligada à diocese para congregar candidatos ligados a questões religiosas, sobretudo as ligadas ao combate ao comunismo e ao divórcio e em defesa de prerrogativas do ensino religioso no campo educacional. O programa da ALEF foi divulgado no boletim da cúria diocesana em março de 1962. Entre os pontos destacados pela equipe estavam:

- Combate a todas as medidas que atentem contra os direitos e a respeitabilidade da instituição família, fundada no casamento com vínculo indissolúvel;

- Amparo e proteção à natalidade; revogação de qualquer dispositivo legal que possa prejudicar o direito do nascituro à vida;

- Combate ao comunismo, sua doutrina, propaganda e a qualquer de suas atividades;

- Rejeição de todo monopólio educativo, defesa do ensino religioso facultativo nos estabelecimentos oficiais.

Em relação à política internacional, mencionava-se a "resistência à expansão de todo imperialismo, expresso pela dominação das nações mais fracas pelas mais fortes" e a toda política internacional totalitária, seja comunista ou fascista, abraçando uma política democrática e anti-ditatorial. As exigências da ALEF estavam em grande conformidade com a Matter et Magistra, encíclica papal lançada em 1961 por João XXIII, na ocasião das festas de cinquenta anos da Rerum Novarum, a encíclica que inaugurou os posicionamentos da Igreja nas questões da sociedade moderna e industrial. Nela, como vimos, o papa pedia que a Igreja não abraçasse o comunismo, nem o liberalismo exacerbado como caminho para uma sociedade justa e fraterna, mas agisse na "terceira via" dos dois modelos, sob a consciência 
cristã. Este núcleo da mensagem da Doutrina Social da Igreja também será debatido nos boletins da Cúria de São Carlos dos anos da ditadura.

Em 1962, a ALEF, com objetivo de orientar os votos dos fiéis são-carlenses, indicou uma lista de candidatos aos pleitos do governo do estado de São Paulo, Assembleia Legislativa e Câmara Federal. A lista foi aprovada pelo bispo diocesano e enviada, via boletim mensal da cúria, a todas as paróquias da diocese, onde os padres deveriam repassar o levantamento feito pela entidade a seus fiéis. As chamadas nos boletins diocesanos traziam os dizeres: “A Aliança Eleitoral Pela Família, já amplamente aprovada e abençoada pelo Episcopado, será valioso instrumento na orientação do eleitorado”.

Após as eleições, foi enviada outra lista, agora dos nomes dos eleitos dentre aqueles que haviam sido indicados e se comprometido com a ALEF de todo o estado de São Paulo. Os resultados apontam para 29 deputados federais e 61 deputados estaduais, segundo o documento, representando mais de $50 \%$ das cadeiras disponíveis nas casas legislativas. Estavam também na lista de eleitos o vice-governador Laudo Natel (que se candidatara por faixa própria pelo Partido Republicano) e o senador Auro de Moura Andrade, do Partido Social Democrático, o PSD.

Ernesto Pereira Lopes, "cabeça” da UDN em São Carlos, estava na lista da ALEF e já se destacara nas eleições legislativas federais, em grande parte porque conseguia arcar com os custos da campanha a âmbito regional, e se elegeu como deputado federal em três mandatos (SGUISSARDI, 1993, p. 30). Durante o regime militar, Lopes filiou-se ao partido do governo, a Aliança Renovadora Nacional (ARENA), pela qual foi deputado federal em mais dois mandatos. Era líder de um importante grupo de industrialistas e sócio de um jornal na cidade, o Correio de São Carlos, conhecido pelo forte combate ao comunismo.

Segundo René Dreifuss (1987), o grupo empresarial de Ernesto Pereira Lopes teria sido um dos patrocinadores da ação do IPES (Instituto de Pesquisa e Estudos Sociais) e IBAD (Instituto Brasileiro de Ação Democrática) na articulação da campanha para a derrubada do presidente João Goulart em 1964. O político era ainda tido como um católico assíduo aos eventos religiosos, amigo pessoal do bispo dom Ruy Serra e generoso nas doações que fazia às obras da diocese (PAINO, 2002).

Havia em São Carlos um padre fortemente ligado às causas sindicais. Seu nome era Antônio Tombolato e logo que chegou como vigário da catedral de São Carlos teria disponibilizado os salões da catedral para os operários, cooperando diretamente para a formação do Sindicato dos Metalúrgicos de São Carlos e organizando a Juventude Operária Católica, a JOC. O padre teria participado da catalogação e denúncia das infrações 
trabalhistas e situações vigentes nas Indústrias Pereira Lopes, no início da década de 1960: maus tratos, violência e arbitrariedades, como não poder ir ao banheiro ou beber água, exceto em horários predeterminados, além dos atrasos constantes no pagamento dos salários. Os padres diocesanos Arlindo Zanotti e Antônio Desan, passaram a dar suporte ao padre Tombolato nesse empreendimento a favor dos trabalhadores.

Com as fortes críticas dos trabalhadores, auxiliados pela Juventude Operária Católica, a Ernesto Pereira Lopes e a seu irmão - o diretor da empresa, Mario Pereira Lopes, em 1961 -, as lideranças políticas e empresariais da cidade teriam organizado, em resposta, um ato em desagravo às "calúnias" dos sindicalistas à direção do grupo IPL. O evento no São Carlos Clube teria somente um orador oficial: Dom Ruy Serra. Segundo José Roberto Paino, um advogado envolvido nas questões sindicais e políticas da cidade, “o bispo não poderia deixar de mostrar que era um bispo muito amigo dos patrões" (2002, p.73), e os trabalhadores não teriam ficado surpresos por essa indicação de orador.

Conforme Pe. Tombolato assumia lugar de destaque na luta sindical ao lado de Antônio Cabeça Filho, o principal sindicalista desse período, surgiu uma tensão política em torno da participação da Igreja na atividade política da cidade. Ainda segundo Paino (2002, p.20), dom Ruy Serra "foi acusado pelos industriais e pela elite conservadora de São Carlos como tendo trazido para a cidade grupos da ala progressista da Igreja, que poderiam causar 'prejuízos aos industriais e à paz reinante da sociedade"'. Atendendo à pressão do empresariado, o padre Tombolato foi transferido da região central para a vila mais pobre da época, a Vila Isabel, e seus apoiadores, Zanotti e Desan, para cidades vizinhas a São Carlos, pertencentes ainda à mesma diocese. Mesmo assim, o sacerdote continuou acompanhando os operários, que conseguiram criar seu sindicato em 1962.

O caso é emblemático e merece atenção. Diversas fontes da época apontam a proximidade do bispo aos industriais da cidade, sobretudo a Ernesto Pereira Lopes. Nas eleições, o apoio do bispo era para a UDN e, posteriormente, para a ARENA, o que podia não se verificar nas paróquias, pois os padres costumavam apoiar candidatos mais populares. Dom Ruy Serra, nesse momento de tensão sindical, claramente usou de sua autoridade hierárquica e o aparelho institucional do qual dispunha na diocese para desarticular os críticos de sua rede social - rede composta por grupos que se ligaram ao regime militar após o golpe.

A Indústria Pereira Lopes, de um modo geral, era a que encontrava maior conflito com os sindicalistas. Além do carro-chefe do grupo, a produção de geladeiras (que chegou à marca de um terço de toda a produção nacional), a IPL passou a produzir os componentes a serem utilizados na geladeira e, por fim, lançou também uma frente de produção de 
maquinários, a Companhia Brasileira de Tratores, a CBT. Os conflitos entre os trabalhadores e os funcionários se tornaram mais evidentes com a presença de Dom Jorge Marcos de Oliveira, bispo de Santo André, São Paulo, conhecido como “o bispo operário”, que atacava claramente os industriais, especialmente Ernesto Pereira Lopes, em seu discurso, quando algumas vezes esteve presente na cidade a convite dos operários de São Carlos para palestras (PAINO, 2002, p. 42).

Havia uma tensão política entre dom Ruy Serra e dom Jorge Marcos, o primeiro mais alinhado com os industriais e o segundo com os operários. Ligado a importantes institutos do Vaticano, Dom Jorge Marcos não precisava de autorização do bispo local para vir até São Carlos se dirigir aos operários. Seu forte discurso sindicalista agradava os trabalhadores e desagradava os empresários e a direita política. O capitalismo frequentemente era alvo de suas críticas e, no caso de São Carlos, as indústrias de Ernesto Pereira Lopes:

Não podemos concordar com essa exploração a que estão submetidos os trabalhadores da IPL. Se riscarmos as geladeiras delas sairão não gotas de sangue dos trabalhadores, mas jorrará uma enorme quantidade de sangue proletário em virtude da escravidão e do tratamento desumano dado por essa indústria aos trabalhadores (Dom Jorge Marcos apud PAINO, 2002, p.48).

O bispo de Santo André esteve presente na ocasião da fundação do Sindicato dos Metalúrgicos, na qual, segundo Paino (2002, p.48), os operários gritavam em coro, no auditório da Rádio São Carlos: "Um, dois, três, com dom Jorge Marcos patrão não tem vez".

O clima que antecedia o golpe militar no Brasil foi sentido em São Carlos. Em janeiro e fevereiro do ano de 1964, imprimiram-se nas edições do jornal Correio de São Carlos uma campanha de arrecadação de fundos para o que chamaram de "Caminhada de Carlos Lacerda à Presidência". O governador da Guanabara foi apontado pelo jornal como a "última esperança, um administrador de verdade, suficientemente esclarecido e com visão necessária para dar à sua pátria o governo que ela realmente precisa" (Correio de São Carlos, 26 de fevereiro de 1964). Um cupom de ordem de pagamento impresso no jornal foi publicado três vezes no mês de março, acompanhado dos dizeres:

Carlos Lacerda na Presidência da República é a chave para a solução dos problemas do Brasil. É a chave que fechará as portas da corrupção. Lacerda é a chave de mais tetos, de mais hospitais, de mais indústrias e mais alimentos para o povo. Lacerda é a chave símbolo para dar Ordem e Progresso para o Brasil. E você, brasileiro, é a chave para levar Lacerda à Presidência da República. Para isto, dê seu voto, dê seu trabalho e dê contribuições financeiras para a Campanha CL 65. Se você mora no Rio 
ou em São Paulo, deposite sua contribuição em qualquer Banco de sua cidade em nome da CAMPANHA NACIONAL CARLOS LACERDA. Se você mora no interior, envie uma ordem de pagamento, conta qualquer agência de qualquer banco da Guanabara. (Correio de São Carlos, 26 de fevereiro de 1964)

No boletim da cúria do mês de fevereiro de 1964, o texto da primeira página, denominado "Orientações", trazia observações sobre a realidade política brasileira, bem consoante com os posicionamentos da própria CNBB. Pedia, primeiramente, para que os católicos (leigos e religiosos) não aceitassem ser rotulados como de esquerda ou de direita, ou ainda como reacionários ou progressistas, por favorecer posições inexatas e a desunião dos católicos. Assim, recomendava aos fiéis que não aceitassem sem desconfiança o anticomunismo meramente negativo e nem subestimassem a infiltração marxista nos setores da sociedade, não assumindo uma postura "conservadora e passadista de fechamento em face da realidade do Brasil" e nem uma "aceitação total e imprudente, sem crítica de todo o processo de renovação social chegando a identificar-se com métodos marxistas que visam a revolução brasileira, no sentido vermelho".

A grande adesão da população paulistana à Marcha da Família com Deus pela Liberdade, no dia 19 de março, deu ânimo para que os grupos anticomunistas do interior se organizassem. Em 21 de março, ocorreu a Marcha na cidade de Araraquara. No editorial do Correio de São Carlos, no dia 26 do mesmo mês e dias antes do golpe que instituiu o regime militar, Dom Ruy Serra escreveu, convocando a cidade de São Carlos a se organizar e comparecer:

São-carlenses! Vamos comparecer em massa, em praça pública, na "Marcha da Família com Deus pela Liberdade" a fim de fazer ouvir a nossa voz, que é a voz dos brasileiros que amam a sua pátria, que é a voz do Brasil, que não é a voz dos assalariados que pedem o fechamento do congresso e o cerceamento de nossas liberdades, mas a voz que clama por um Brasil com Deus, pela pátria livre de ditaduras e pela família cristã.

O editorial do Correio de São Carlos, de 29 de março de 1964, retoma a chamada do bispo e reforça o perigo eminente que a sociedade corria se o comunismo triunfasse:

Sob todos os aspectos, a vigorosa palavra de Dom Ruy Serra soou aos sãocarlenses indistintamente como a palavra ansiosamente esperada, o brado de incentivo à ação há muito aguardado, um alerta contra o comunismo anti-cristão (...) Quem pode afirmar que a palavra de Dom Ruy não é a de um líder consciente, patriota, que conclama seu rebanho à tomada de posição contra aqueles que querem implantar em nossa terra o mais negro e odioso regime de escravidão, de opressão, de fome e de morte, o comunismo ateu, inimigo de Deus, da Pátria e da Família. 
Como o golpe ocorreu em 31 de março, o protesto marcado para o dia 2 de abril se tornou uma manifestação comemorativa, remarcada para dia 6 do mesmo mêsCom o nome "Marcha com Deus pela Vitória da Democracia", comemorava o que o Correio de São Carlos chamou de "vitória das forças democráticas na luta contra o comunismo", contando com a participação do bispo diocesano Dom Ruy Serra por um trecho da caminhada. Logo no primeiro dia do regime, os líderes sindicais Antônio Cabeça Filho, Manfredo Formigonni e Benedito Carlos Pereira foram presos por ligação com o Partido Comunista Brasileiro e, no dia seguinte, nove vereadores de São Carlos lançaram uma nota apoiando o golpe (SILVA, 2009, p. 64).

\title{
3. SÃO CARLOS E O REGIME MILITAR: A HISTÓRIA POLÍTICA E A AÇÃO DO EPISCOPADO
}

No dia 13 de abril de 64 a Câmara Municipal de São Carlos saúda a "Revolução" e pede a cassação de direitos políticos dos vereadores suplentes. A notícia, veiculada no Correio de São Carlos, dizia:

\begin{abstract}
Durante a sessão Ordinária levada a efeito ontem pela Câmara Municipal de São Carlos, com a presença da totalidade dos senhores vereadores, foi aprovado importante requerimento endereçado ao Comando Supremo da Revolução Democrática de 31 de março

O requerimento, de extrema urgência, aprovado por unanimidade, solicita providências dos Comandantes Supremos da Revolução e do Sr. Presidente da república, no sentido de serem investigadas a atuação de quatro suplentes de vereadores à Câmara Municipal de São Carlos e, sendo constatada a atividade antidemocrática dos referidos suplentes, ser efetuada a imediata cassação de seus direitos políticos.

São pessoas implicadas em todas as agitações de caráter político e social que foram promovidos (sic) nesta cidade, em afrontoso atentado à Constituição e à ordem jurídica da Nação.

Estes suplentes poderão eventualmente ser convocados, em afrontoso atentado à Constituição e à ordem jurídica da Nação. São eles: Benedito Carlos Pereira (PSP), Manfredo Formigoni (PR), Newton Fonseca de Andrade (PTN) e José Roberto Andrade Paino (PTN).
\end{abstract}

No boletim da cúria diocesana de abril de 1964, o bispo envia para todas as paróquias a carta dos bispos da Regional Sul 1 da CNBB, denominada Manifesto do Episcopado Paulista ao Povo Brasileiro (Figura 1), do qual é signatário, pedindo que rezem pela paz na Pátria e não peguem em armas, de forma a evitar derramamento de sangue: 
Figura 1 - Dom Ruy Serra circula pela diocese a posição dos bispos de São Paulo frente ao golpe militar

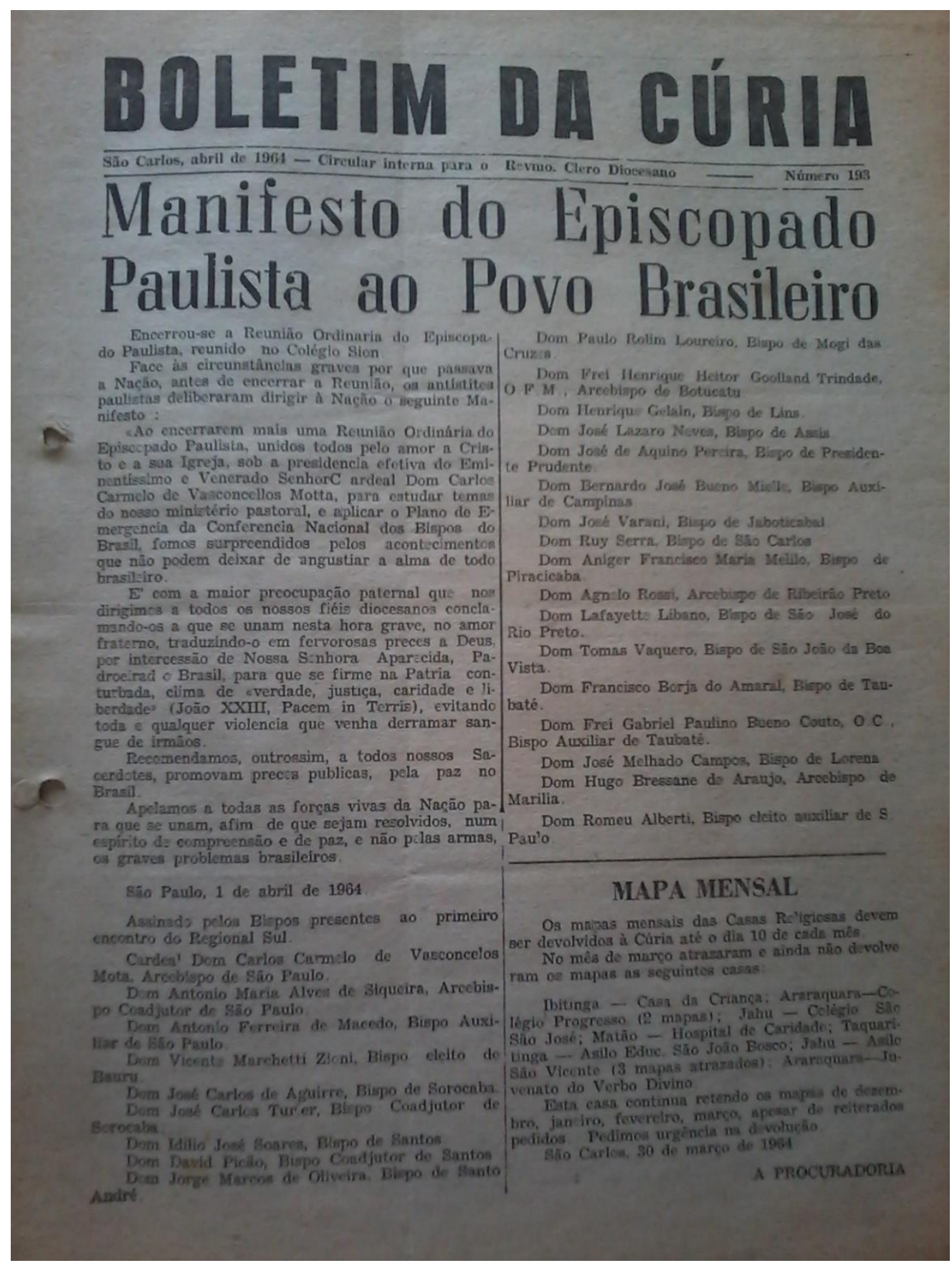

Fonte: Arquivo da Diocese de São Carlos.

O boletim da cúria diocesana enviado às paróquias de São Carlos no mês de maio trazia uma mensagem dos bispos do estado de São Paulo dirigida aos trabalhadores, que tratava de pontos políticos e sociais da conjuntura do país.

Passado o primeiro impacto dos acontecimentos político-sociais que sacudiram a Nação, organizado o novo governo que deverá reger os 
destinos do país, chegou o momento de dirigirmos com mais vagar ao clero, aos religiosos e fiéis de nossas dioceses, uma palavra de conforto e orientação. Julgamos que não será demasiado agradecer a Deus, ainda uma vez, pelo que de positivo teve e continua tendo o movimento político militar de março último. Com satisfação igual vemos a nova ordem implementar em nossa pátria e debelar totalmente o perigo do comunismo que já assumia proporções assustadoras com propósitos inaceitáveis na mais justa e inadiável das campanhas reformistas.

Após essa introdução, os bispos lamentavam a "confusão dos primeiros momentos de luta, sobretudo a respeito da Ação Social e da Ação Católica". O trecho se refere ao fato de vários agentes de pastoral, sobretudo os que trabalhavam em causas operárias, camponesas e estudantis no Nordeste, terem sido presos sob acusações de comunismo, conspiração ou questões de segurança nacional logo após o golpe de Estado. Reforçando o argumento assumido por essa pesquisa - o da autonomia do bispo para julgar os acontecimentos dentro da jurisdição de sua diocese -, o documento diz que "aos bispos, sucessores dos Apóstolos em cada diocese, cabe a justificação de seus programas e métodos da fidelidade da evangelização e da prudência do agir de seus militantes”.

Esta carta de maio de 64, - da qual Dom Ruy Serra é signatário -, retomou os princípios da Doutrina Social da Igreja, repudiando tanto o comunismo como o liberalismo econômico e solicitava ainda que os meios de comunicação fossem honestos; que não se abandonassem as reformas sociais; que se atentasse às necessidades das pessoas privadas de direitos essenciais e fazia ainda uma defesa de um sindicalismo "livre e legítimo". O documento termina deixando explicita a preocupação dos bispos com o momento histórico e fazendo um apelo à unidade:

Amados irmãos e filhos caríssimos, em nenhuma outra época da História necessitou tanto a Igreja de dar testemunho vivo de unidade interna. Por essa razão alertamos com veemência compatível com a gravidade do momento a todos os fiéis para a responsabilidade que pesa sobre nós de conservar a unidade do espírito no vínculo da paz.

Em 1968, um importante frigorífico da cidade, o frigorífico São Carlos do Pinhal, entrou em falência, e não pagou o salário de mais de 600 operários por vários meses. - o episódio é relatado por Paino (2002) no livro Matizes de uma luta: capitulos tenebrosos da história sindical empresarial e política de São Carlos. A família Fialdini, dona do frigorífico, foi mais uma das empresas atingidas pela guinada política do golpe de 64. Segundo alguns atores sociais e políticos da época, registrados na obra de Paino, o bom relacionamento com a equipe econômica de João Goulart, os Fialdini perderam o crédito nos bancos e no mercado após a tomada do poder pelos militares e, sem subsídio não arcaram com os investimentos que 
haviam planejado. O Sindicato dos Metalúrgicos prestou solidariedade aos funcionários do frigorífico, provendo cestas básicas levantadas em campanhas, dando assistência jurídica e organizando a movimentação social. No quarto mês sem salário, os trabalhadores organizaram uma passeata exigindo a regularização dos salários e chamando a comunidade a colaborar com as vítimas da falência do frigorífico. A manifestação mal iniciou e houve conflito com a polícia, que armou uma barreira de soldados com fuzis e baionetas. Foi efetuada a prisão dos sindicalistas Cabeça Filho, Formigoni, Durval Chinez e Pereira Augusto, os dois primeiros encaminhados à sede do DOPS, o Departamento de Ordem Política e Social, em São Paulo.

Os dois líderes operários sofreram torturas físicas e psicológicas: choques, mutilações e espancamento. Segundo relatou Cabeça Filho (PAINO, 2002, p.152), as perguntas começaram amplas, no sentido de obrigá-lo a revelar (a) "quais as ramificações comunista, cubana, russa ou chinesa" ele pertencia. Num segundo momento, o interesse do delegado que o interrogava era saber informações que pudessem instrumentalizar uma perseguição política a José Bento Carlos do Amaral, candidato a prefeito nas eleições de outubro daquele ano, que iria enfrentar o candidato da ARENA 1, apoiado por Ernesto Pereira Lopes. Com apoio da UNE, a União Nacional dos Estudantes, que havia feito panfletos denunciando a prisão dos sindicalistas, eles foram soltos em 17 de agosto, após o assessor jurídico da Federação dos Metalúrgicos do Estado de São Paulo, Sebastião de Paula Coelho, ir até o DOPS com a determinação de alguma autoridade superior em Brasília, não revelada.

Enquanto isso, os estudantes da Escola de Engenharia da USP de São Carlos, do Centro Acadêmico Armando Salles de Oliveira, o CAASO, decidiram apoiar os operários, marcando uma outra manifestação em prol dos trabalhadores do frigorífico, no dia 15 de agosto. A possibilidade de agitação social se apresentou como "um risco aos ganhos da Revolução" e levou a ocuparem a cidade de São Carlos por uma semana com mais de 5 mil homens. Houve confronto entre os trabalhadores e estudantes e os militares; alguns estudantes foram presos. A cidade ficou em estado de sítio por dois dias: escolas e comércio fechado, entradas bloqueadas e todo veículo que entrasse era revistado e obrigado a se identificar, de modo a evitar que viessem mais pessoas a apoiar a referida manifestação.

O Estado de S. Paulo, no dia 2 de agosto, se referiu à passeata e a Folha de S.Paulo trouxe a manchete: "São Carlos, prefeito vai pleitear intervenção federal no frigorífico". Em 10 de agosto, o mesmo jornal trazia: "São Carlos: a polícia reprime a passeata de operários que não recebem há quatro meses". No dia 16, A Folha de São Carlos publica os desdobramentos da tentativa de manifestação do dia 14: 


\begin{abstract}
"Dia catorze São Carlos virou praça de guerra. Havia soldados por toda parte".

Vieram pelotões de Campinas, Araraquara, São Paulo e, também de outras cidades circunvizinhas se fizeram representar, como Ibaté, Torrinha, Ribeirão Bonito. Havia ainda brucutus, tatus e aviões. Tudo isso porque estava anunciada uma passeata de universitários de apoio aos trabalhadores do Frigorífico.

A cidade ficou totalmente alarmada e viveu um dia completamente diferente. Os alunos foram dispensados das aulas. As lojas, bancos, repartições públicas foram fechadas. Os estudantes, principalmente do Instituto de Educação Álvaro Guião se aglomeraram em frente ao São Carlos Clube. Vieram ônibus de estudantes de diversas localidades.

Cerca de dezenove horas surgiu um início de passeata de estudantes na Avenida Dr. Carlos Botelho, mas partiram em debandada assim que viram a polícia.
\end{abstract}

O Estado imprimiu em sua primeira página a reportagem sobre o ocorrido, sob o título "São Carlos ocupada"; a Folha de S.Paulo: "Tropas ocupam São Carlos para impedir passeatas"; e o jornal Última Hora, mais contundente de todos, trazia a manchete "A Cidade do Medo" e, no dia dezoito, a reportagem nas páginas oito e nove "A verdade sobre são Carlos”, com fotos e depoimentos de pessoas que presenciaram a manifestação. A imprensa nacional noticiou o ocorrido na cidade, dando grande repercussão ao acontecimento político de poucos meses antes da instituição do AI-5, que vai silenciar por um bom tempo as manifestações públicas de oposição como esta.

Em 1968 houve eleições para prefeito na cidade. O partido do governo, a ARENA, concorreu com duas chapas: ARENA 1 e ARENA 2. A instauração do bipartidarismo, em 1965, não fez com que os diversos grupos políticos da cidade se aglutinassem tão facilmente. Havia claras divergências dentro do partido, especialmente entre os provindos da extinta UDN com os dos demais grupos políticos aglutinados na ARENA. O vencedor da disputa eleitoral foi o candidato da ARENA 2, José Bento Carlos do Amaral, que já trabalhava no gabinete do prefeito anterior, Antônio Massei, derrotando Carmine Mota, o candidato que tinha apoio de Pereira Lopes. A chapa da ARENA 2 ainda elegeu dez dos quinze vereadores, demonstrando forte articulação política na cidade, como 2 cadeiras da câmara ficaram com o MDB, a oposição, restam apenas 3 cadeiras para a ARENA 1, mas essa configuração se alterou ao longo da legislatura.

Segundo o prefeito, eleito com $70 \%$ dos votos válidos, José Bento Carlos do Amaral ${ }^{5}$, a rivalidade entre o grupo da ARENA 1 e 2 era muito forte. A sublegenda ARENA1 a que possuía canais sólidos mais com agentes do regime militar, personificado na pessoa de

\footnotetext{
${ }^{5}$ A entrevista completa encontra-se publicada em KOPANYSHYN, 2015.
} 
Ernesto Pereira Lopes, o deputado federal. Logo que tomou posse, o prefeito, que tinha vínculos com o destituído João Goulart antes do golpe, e os vereadores da ARENA 2 sofreram forte pressão para que renunciassem. Ressalte-se que desde 1968, quando o sindicalista Cabeça Filho foi preso, torturado e interrogado, o sistema de inteligência do regime militar visava informações privilegiadas que pudessem ser usadas contra Bento Carlos do Amaral (PAINO, 2002, p.152).

Cinco dos dez vereadores da ARENA 2, que assumiram a legislatura em 1969, renunciaram até o segundo ano de legislatura, todos sem justificativa e logo após serem interrogados pelos órgãos de segurança. Foram eles: Orlando Marques, Miguel Arthur, José Marrara, João Miguel e José Mariutti Seppe, este último presidente da Câmara. Possivelmente, os vereadores sentiam-se ameaçados em sua segurança ao permanecer com a situação e renunciavam, de forma a enfraquecer também o governo de José Bento. O viceprefeito, Alderico Vieira Perdigão, também renunciou poucos dias antes dos vereadores, na primeira semana de janeiro de 1970, após ser preso e levado para São Paulo. Em um ano, o prefeito da cidade enfrentou cerca de 60 inquéritos, inclusive da gestão anterior, e sofria pressão, frequentemente sob ameaças, para que renunciasse:

[...] E outra tortura que eles faziam, comigo era quando eles queriam, não é bem um depoimento, que eu fazia muito, mas eu ficava lá na sala com os torturadores umas 18 horas, de pé! Você não acredita! Chamava Augusto o homem que fazia o inquérito, eu dizia: "Seu Augusto, o senhor permite que eu vá no mictório?” Ele dizia, "não!", cheguei a fazer as necessidades na calça, não podia sair do lugar!

Eles faziam muito, assim, isso no final, você ficava esperando num chá de cadeira duas horas, três horas. Esse tal de Augusto gritava pra fora: "Fulano, o carro de São Carlos já veio?" e o cara lá de fora respondia, tudo mancomunado, "Não, ainda não, seu Augusto!". Isso 4 ou 5 vezes, você ficava esperando. Chegou uma hora que esse Augusto disse pra mim: "Prefeito, o senhor não está interessado em saber que carro vai vir de São Carlos?”, eu falei: "Não...", "sabe quem nós mandamos prender em São Carlos?" eu falei: "não..." eu era meio gozador, ele continuou: "A tua mulher! Ela deve ser bonita, mulher de ladrão, deve ter roupas finas, a soldadesca vai se divertir a noite com ela aqui". [...] Então, tinha esses lances, assim, pra ver se eu renunciava, que a missão dele era que eu renunciasse ao cargo. Esse dia que eu fiquei 18 horas, eu estava que não aguentava, todo molhado, sem beber água, desidratado, então eu não estava aguentando. Eu olhei na sala e olhei na gaveta, assim e pensei: vou quebrar a mão. Cheguei a pensar em colocar a mão, assim, fechar a gaveta e quebrar os dedos. [...] Então, esses efeitos de tortura, mais moral, isso era constante, constante, constante, constante. Eles não tinham o menor respeito pela pessoa. Para eles nós éramos tudo ladrão, tudo bicho, então eles judiavam (José Bento Carlos do Amaral, entrevista em 16/01/2015). 
Em 1970, o Ministro da Justiça, Alfredo Buzaid, decretou um ato de intervenção no município, que ocorreu no mês de abril. O escolhido como interventor federal foi Antônio Teixeira Vianna, que era diretor da EMBRAPA em São Carlos. A acusação foi de corrupção, no período em que o prefeito José Bento Carlos do Amaral trabalhava no gabinete do prefeito anterior, Antônio Massei. José Bento fora afastado para que "as questões fossem averiguadas". Passados os três anos até o fim do mandato, o processo foi arquivado, sem provas conclusivas, e as eleições de 1974 ocorreram com vitória do candidato da ARENA 1. Segundo Amaral, o bispo Dom Ruy Serra foi um dos depoentes contra ele em um dos inquéritos que enfrentou, no qual questionava a integridade do então prefeito, dizendo não o conhecer quando, na verdade teria sido frequentador da casa da família Botelho do Amaral. Do ponto de vista do ex-prefeito da cidade, este posicionamento do bispo visava defender os interesses do grupo de Ernesto Pereira Lopes.

A sociedade civil fomentava, via jornais locais ou organizações, o discurso próprio dos defensores da "Revolução". Uma entidade que merece destaque é a União Cívica Feminina (UCF), que trazia como lema "Família e democracia". Importante frisar que a entidade estava na articulação das Marchas da Família com Deus pela Liberdade. Em São Carlos, a UCF desempenhou um papel fundamental de difusão dos ideais do grupo que se intitulava "Revolucionários de 1964". Para além dos cursos de culinária, corte e costura e outras atividades para as senhoras católicas da cidade, o próprio nome diz que a razão de ser da organização é cívica. Assim, as senhoras da elite são-carlense promoviam atos que consideravam de conscientização da situação política e solenidades comemorativas de datas que consideravam importantes.

As comemorações de Aniversário da Revolução de 64 - em 31 de março -, a festividade da Revolução Constitucionalista - em 9 de julho - e as comemorações da Independência do Brasil - em 7 de setembro - eram organizadas com a direta participação da União Cívica Feminina. Próxima à figura do bispo diocesano Dom Ruy Serra, muitas de suas reuniões e solenidades ocorriam na sede do bispado, algumas com a participação do bispo, como o caso das missas em Ação de Graças ao aniversário da Revolução de 64. No jornal local, $A$ Folha, é encontrada a convocatória para celebração da referida missa presidida pelo bispo diocesano em todos os anos de chumbo, ou seja, de 1969 a 1974. A pedido da UCF, foi celebrada em 13 de setembro de 1969 uma missa votiva pela recuperação do então Presidente da República, Costa e Silva.

Em 1971, o deputado Ernesto Pereira Lopes assumiu, com a aprovação do próprio presidente da república, Garrastazu Médici, a presidência da Câmara dos Deputados no 
Congresso Nacional. No ano seguinte, o presidente Médici faria uma visita à fazenda de Pereira Lopes em São Carlos, durante um final de semana. Em depoimento a seus biógrafos, (VALENTE. HUMBERG, 1994), após a redemocratização, o ex-deputado afirmou que se aproveitou da oportunidade de outubro de 1972, estando próximo a Médici para sugerir que o presidente começasse os esforços para a "institucionalização da Revolução", o que não agradara o militar e supostamente teria prejudicado os próximos passos na carreira política de Pereira Lopes. Seu adversário político da época, José Bento Carlos do Amaral, no entanto, afirma que Pereira Lopes se beneficiava muito da estrutura do regime e que Médici não fez qualquer esforço para conhecer a cidade, apenas passando de carro pelo centro quando a visitou, sequer comparecendo para receber o título de cidadão honorário conferido pela câmara dos vereadores na ocasião.

Após 1971, Dom Constantino Amstalden também atuou na diocese, como bispo coadjutor de dom Ruy Serra. As publicações, assinadas por ele no período do regime militar, marcam questões que são de ordem interna e sem muita visibilidade política. A exceção se dá no tocante às questões relacionadas ao divórcio, onde o bispo articula junto à Câmara Municipal e São Carlos assinaturas para pressionar o Congresso Nacional a não aprovar a "lei do divórcio", em 1975.

\section{CONSIDERAÇÕES FINAIS}

O bispo titular de São Carlos, reconhecido pela sua pontualidade impecável, poucas vezes se manifestou publicamente, ao menos no que foi possível encontrar nos documentos históricos, no que se refere à situação política do país, não sobressaindo um posicionamento claro como no caso dos bispos das capitais do país. Contudo, é possível acompanhar algumas evidências de seu posicionamento.

A relação de Dom Ruy Serra com o deputado da UDN/ARENA, Ernesto Pereira Lopes, parece ser um dos determinantes. O empresário e deputado influenciava diretamente determinadas escolhas do bispo, como vimos no caso da tentativa de desvincular o sindicato dos metalúrgicos da imagem da catedral, o desagravo em favor da família Lopes e a tensão com o bispo de Santo André diante dos operários. O jornal O Correio de São Carlos - ligado a Pereira Lopes, e que poderia apresentar um posicionamento mais preciso do bispo em relação ao governo militar, por ser um jornal mais conservador e do lado da situação no período de maior tensão entre o Estado e a Igreja - não se encontra em nenhum dos arquivos públicos da cidade: o jornal, intencionalmente ou por uma fatalidade desconhecida, não está arquivado nos anos 1966-1982, nos dois principais arquivos públicos, a Fundação Pró- 
memória de São Carlos e a Unidade Especial de Informação e Memória da Universidade Federal de São Carlos.

Ao convocar a Marcha da Família com Deus pela Liberdade e caminhar com ela quando se tornou marcha da Vitória; ao ser signatário do documento da Regional Sul 1 da CNBB, que somente pede as preces para que o país não pegue em armas e "a pátria alcance a paz'; ao apoiar a União Cívica Feminina nas atividades pró-comemoração da Revolução pelo menos até 1974; ao selecionar os candidatos que não tivessem "ideologias comunistas" para a ALEF; ao tentar organizar os sindicatos via Ação Católica, o bispo se posiciona também, dentro das motivações que norteiam o que ele considera o sentido de missão, como sugeriu Scott Mainwaring em Igreja e Politização no Brasil. As pastorais sociais ocorriam mais voltadas ao antigo modelo da Ação Católica Brasileira que no sentido pós conciliar proposto pela CNBB. Também não foram encontrados registros de alguma manifestação pública que contestasse a legitimidade do regime militar. Por fim, não foi instituída na diocese de São Carlos a Comissão de Justiça e Paz, desde 1972 presente em algumas dioceses de São Paulo, de modo que não havia mecanismos institucionais que pudessem servir de canal para a articulação da diocese em favor de perseguidos políticos através da rede do bispo diocesano.

Dentro das disputas de memória histórica, o bispo é visto pelos sindicalistas e populistas como distante da população mais pobre, um “aliado dos patrões e próximo à elite", sendo acusado, inclusive, de testemunhar contra o prefeito José Bento Carlos do Amaral em 1970, na ocasião da intervenção federal para defender o projeto político de Pereira Lopes para a cidade, à revelia da vontade popular expressa pela eleição. Por parte da Igreja, é lembrado como um bispo sério e pontual nas colunas da história da diocese, a quem pouco ou nada agradava ver o clero envolvido com questões políticas, que foi o construtor da nova catedral. O bispo da Ação Católica, sobretudo na atividade social e, eventualmente, eleitoral.

Tenha sido pela escassez de documentos, tenha sido pela elaboração dos discursos acerca da imagem de Dom Ruy Serra, a pesquisa aponta uma ação política conservadora e fortemente influenciada pela conjuntura de grupos política e economicamente importantes na cidade São Carlos.

Por fim, em que pese que a Igreja Católica teve papel importante na legitimação dos militares no poder, no golpe de 1964, também foi âmbito fundamental em muitos lugares para as críticas mais contundentes ao regime militar, quanto à tortura, desaparecimentos e, posteriormente, requerendo o Estado de Direito, a Anistia e redemocratização do Brasil. Mas o papel político desempenhado pela Igreja Católica durante a ditadura militar é complexo e 
a autonomia que os bispos têm dentro de sua circunscrição exige ainda trabalhos profundos e novos recortes temporais e geográficos, ampliação do acesso aos documentos sobre o assunto nas instituições, que tragam à luz novos dados que gerem, por fim, análises cada vez mais precisas. Com esse estudo da diocese de São Carlos, este artigo espera ter contribuído para a análise política e a memória histórica do tema.

\section{REFERÊNCIAS}

BRUNEAU, T. 1974. O catolicismo brasileiro em época de transição. São Paulo: Loyola.

DREIFUSS, R. 1987. 1964: a conquista do Estado. Petrópolis: Vozes.

GERRING, J. 2001. Social Science Methodology: A Criterial Framework. Cambridge: Cambridge University Press.

KERBAUY, M. T. M. 1979. Poder Político Local: do coronelismo ao populismo (um estudo de caso: São Carlos), Tese de Doutorado, São Carlos: UFSCar.

KOPANYSHYN, E. 2015. A ação política dos bispos católicos na ditadura militar: os casos de São Carlos e Assis. Dissertação de Mestrado. Universidade Federal de São Carlos.

MAINWARING, S. 1989. Igreja Católica e Política no Brasil. São Paulo: Brasiliense.

PAINO, J. R. A. 2002. Matizes de uma luta: capitulos tenebrosos da história sindical, empresarial e política de São Carlos. São Calos: Suprema.

PERES. P.S. 2008. Comportamento ou instituições? A evolução histórica do neoinstitucionalismo na Ciência Política. Revista Brasileira de Ciências Sociais, vol.23, nº6.

SGUISSARDI, V. 1993. Universidade: fundação e autoritarismo - o caso da UFSCar. São Paulo: Estação Liberdade.

SILVA. J.P. 2009. Comunismo não! A influência do jornal Correio de São Carlos na construção do anticomunismo no município entre 1934-1964. São Carlos: Fundação Pró-memória de São Carlos. SOUZA LIMA, L.G. 1979. Evolução Política dos católicos e da Igreja no Brasil: hipóteses para uma interpretação. Petrópolis: Vozes.

TRUZZI, O. 2007. Café e Industria São Carlos: 1850-1950. São Carlos: Educar.

VALENTE, C. HUMBERG, F.1994. Ernesto Pereira Lopes, um homem três dimensões. São Carlos: JMJ LTDA. 


\section{Acervos documentais:}

Arquivo Ana Lagoa, da Universidade Federal de São Carlos.

Arquivo da Cúria Diocesana de São Carlos

Arquivo do Estado de São Paulo, Memória Política.

Fundação Pró-Memória, Prefeitura Municipal de São Carlos 